\title{
A BNCC E A COMPETÊNCIA ARGUMENTATIVA EM FILOSOFIA NO ENSINO MÉDIO
}

\author{
Izanete de Medeiros Costa ${ }^{1}$ \\ Antonio Júlio Garcia Freire ${ }^{2}$
}

\begin{abstract}
Resumo: O presente artigo tem por objetivo discutir o ensino de Filosofia na Educação Básica brasileira apontando as possíveis alterações que a referida disciplina poderá sofrer com as mudanças preconizadas pela Base Nacional Comum Curricular (BNCC). O texto ressalta a importância do ensino da Filosofia para o desenvolvimento ou aprimoramento da competência da argumentação. A prática argumentativa está presente em diferentes metodologias filosóficas. Esse artigo limita-se a análise da metodologia elêntica presente nos diálogos socráticoplatônicos, mais especificamente no Laques. A argumentação é apontada pela BNCC como uma das competências gerais que deverão ser desenvolvidas pelos alunos da Educação Básica. A flexibilização proposta pela BNCC poderá ter como consequência a exclusão ou minimização dos conteúdos de algumas disciplinas, entre elas a Filosofia. Outro fator preocupante é que, devido a BNCC orientar a organização dos conhecimentos por competências e habilidades e não por disciplinas, um professor sem formação específica na área poderá ministrar conteúdos de Filosofia. Além do domínio de conteúdos específicos, o ensino de Filosofia requer do professor uma postura filosófica, necessária para que os alunos desenvolvam uma argumentação filosófica consistente, definindo conceitos, analisando criticamente diferentes pontos de vista e posicionando-se de forma coerente.
\end{abstract}

Palavras-chave: Ensino de Filosofia. BNCC. Elenchos. Argumentação.

\section{BNCC AND ARGUMENTATIVE COMPETENCE IN PHILOSOPHY CLASSES IN HIGH SCHOOL}

\begin{abstract}
This paper aims to discuss the teaching of Philosophy in Brazilian High School, according to the changes proposed by the Common National Curricular Base (BNCC). Our focus is on the importance of teaching Philosophy to improve argumentation as a competence to be developed by students. The exercise of argumentation can be verified in several philosophical methodologies. This account is limited to a brief analysis of the elentic methodology developed in Laches, one of the Platonic dialogues. The ability to argue correctly is pointed out by BNCC as one of the general competences that should be developed by High School students. However, the curriculum flexibility and the focus of acquiring knowledge on competence and skills proposed at BNCC may result in the exclusion of content from some school subjects, including Philosophy. Any teacher without a specific degree in Philosophy could teach philosophical content. Teaching Philosophy requires a philosophical training of the teacher and it is necessary in order that students can improve their philosophical argument, define concepts correctly, critically analyze different points of view and position yourself in a coherent way.
\end{abstract}

Keywords: Philosophy Teaching. BNCC. Elenchos. Argumentation.

1 Professora Permanente da Secretaria Estadual de Educação e Cultura do Rio Grande do Norte - SEEC/RN. Mestra em Filosofia pela Universidade do Estado do Rio Grande do Norte - UERN. E-mail: izanete@ymail.com.

2 Professor Adjunto da Universidade do Estado do Rio Grande do Norte - Programa de Mestrado Profissional em Filosofia - PROF-FILO, Núcleo Caicó (RN). E-mail: antoniojulio@uern.br. 


\section{Introdução}

No contexto da educação brasileira, a disciplina Filosofia foi retirada da grade curricular diversas vezes. Com a descontinuidade da Filosofia na Educação Básica, essa disciplina passou a ser desvalorizada, sendo muitas vezes ministrada por professores sem formação adequada. Com isso, há prejuízo ao processo de ensino-aprendizagem, visto que tal disciplina contribui significativamente para o aprimoramento do pensamento crítico e da prática argumentativa. Para que os alunos desenvolvam essas habilidades por meio do ensino de Filosofia é importante que essa disciplina seja ministrada por profissionais da área.

A mais recente tentativa de exclusão da Filosofia enquanto disciplina obrigatória se deu por meio da Medida Provisória n ${ }^{\circ}$ 746, de 2016 (BRASIL, 2016), que trata da reformulação do Ensino Médio. A medida provisória determina que apenas o ensino de Língua Portuguesa, Matemática e Língua Inglesa seja obrigatório nas três séries que compõem o Ensino Médio. A medida afirma ainda que o currículo do Ensino Médio deve ser formado por uma Base Nacional Comum Curricular (BNCC) e por itinerários formativos com ênfase nas áreas do saber presentes no Ensino Médio e na formação técnica e profissional (BRASIL, 2016). Desse modo, a Filosofia é retirada mais uma vez da Educação Básica.

A lei $\mathrm{n}^{\circ}$ 13.415, de 16 de fevereiro de 2017 (BRASIL, 2017a), assevera que a BNCC do Ensino Médio contemplará, obrigatoriamente, estudos e práticas de filosofia, sociologia, artes e educação física (BRASIL, 2017a). Desse modo, a lei n 13.415/17 (BRASIL, 2017a) reitera a permanência dos conhecimentos de filosofia no nível médio de ensino, mas não lhe dá o caráter de disciplina. Ainda no ano de 2017, no mês de dezembro, é publicada a resolução CNE/CP n ${ }^{\circ} 2$ (BRASIL, 2017b), que institui e orienta a instituição da BNCC em todas as etapas e modalidades da Educação Básica. Essa resolução reafirma que o ensino deve ser organizado a partir de áreas conforme já havia sido anunciado na Medida Provisória n 746, de 2016 (BRASIL, 2016).

\section{O Ensino de Filosofia e a BNCC}

Com a aprovação da BNCC a educação nacional sofreu novas alterações. Mais uma vez a Filosofia, assim como outras disciplinas, voltou a correr o risco de ficar à margem do ensino. A Base Nacional Comum Curricular (BNCC) é um documento que norteia a Educação Básica brasileira. De acordo com o Ministério da Educação (BRASIL, 2018, p. 7), a BNCC

\begin{tabular}{|c|c|c|c|c|}
\hline Rovista Dialectus & Ano 9 & n. 20 & Outubro - Novembro 2020 & p. $56-70$ \\
\hline
\end{tabular}


é um documento de caráter normativo que define o conjunto orgânico e progressivo de aprendizagens essenciais que todos os alunos devem desenvolver ao longo das etapas e modalidades da Educação Básica, de modo a que tenham assegurados seus direitos de aprendizagem e desenvolvimento, em conformidade com o que preceitua o Plano Nacional de Educação (PNE). Esse documento normativo aplica-se exclusivamente à educação escolar.

A BNCC é guiada pelo princípio da Educação Integral. O documento define um conjunto de saberes essenciais que deverão ser adquiridos pelos estudantes ao longo da Educação Básica. A BNCC começou a ser discutida no ano de 2015. Em 2016, a Medida Provisória n 746, de 2016 (BRASIL, 2016), que trata da reformulação do Ensino Médio já anunciava que o currículo do Ensino Médio seria formado por uma base comum e uma parte diversificada formada “[...] por itinerários formativos específicos definidos em cada sistema de ensino e com ênfase nas áreas de linguagens, matemática, ciências da natureza, ciências humanas e formação técnica e profissional” (BRASIL, 2016, p. 2). A versão final da BNCC/Ensino Médio foi aprovada pelo Conselho Nacional de Educação e homologada em dezembro de 2018.

A BNCC define competências gerais para a Educação Básica. Essas competências são organizadas por áreas do conhecimento: 1. Linguagens e suas Tecnologias; 2. Matemática e suas Tecnologias; 3. Ciências da Natureza e suas Tecnologias; 4. Ciências Humanas e Sociais Aplicadas. No documento, a área de Ciências Humanas e Sociais Aplicadas é composta pelos saberes das disciplinas Filosofia, Geografia, História e Sociologia. As competências específicas dessa área são:

COMPETÊNCIA ESPECÍFICA 1 Analisar processos políticos, econômicos, sociais, ambientais e culturais nos âmbitos local, regional, nacional e mundial em diferentes tempos, a partir da pluralidade de procedimentos epistemológicos, científicos e tecnológicos, de modo a compreender e posicionar-se criticamente em relação a eles, considerando diferentes pontos de vista e tomando decisões baseadas em argumentos e fontes de natureza científica [...] COMPETÊNCIA ESPECÍFICA 2 Analisar a formação de territórios e fronteiras em diferentes tempos e espaços, mediante a compreensão das relações de poder que determinam as territorialidades e o papel geopolítico dos Estados-nações. [...] COMPETÊNCIA ESPECÍFICA 3 Analisar e avaliar criticamente as relações de diferentes grupos, povos e sociedades com a natureza (produção, distribuição e consumo) e seus impactos econômicos e socioambientais, com vistas à proposição de alternativas que respeitem e promovam a consciência, a ética socioambiental e o consumo responsável em âmbito local, regional, nacional e global. [...] COMPETÊNCIA ESPECÍFICA 4 Analisar as relações de produção, capital e trabalho em diferentes territórios, contextos e culturas, discutindo o papel dessas relações na construção, consolidação e transformação das sociedades. [...] COMPETÊNCIA ESPECÍFICA 5 Identificar e combater as diversas formas de injustiça, preconceito e violência, adotando princípios éticos, democráticos,

\begin{tabular}{|c|c|c|c|c|}
\hline Q Rovita Oilatectus & Ano 9 & n. 20 & Outubro - Novembro 2020 & p. $56-70$ \\
\hline
\end{tabular}


inclusivos e solidários, e respeitando os Direitos Humanos. [...] COMPETÊNCIA ESPECÍFICA 6 Participar do debate público de forma crítica, respeitando diferentes posições e fazendo escolhas alinhadas ao exercício da cidadania e ao seu projeto de vida, com liberdade, autonomia, consciência crítica e responsabilidade (BRASIL, 2018, p. 571-578).

Os conhecimentos filosóficos perpassam as competências citadas pela BNCC. A "Competência específica 6" trata de algo que é característico da Filosofia: o debate. Essa competência estava presente nos documentos que regiam o ensino de Filosofia no Ensino Médio (Orientações Curriculares Nacionais - OCNs e Parâmetros Curriculares Nacionais - PCNs) e foi mantida na BNCC. $\mathrm{O}$ ato de debater é indissociável da prática da argumentação. A argumentação é indicada no documento como uma das sete competências gerais da educação básica:

Competências gerais da Educação Básica [...] argumentar com base em fatos, dados e informações confiáveis, para formular, negociar e defender ideias, pontos de vista e decisões comuns que respeitem e promovam os direitos humanos, a consciência socioambiental e o consumo responsável em âmbito local, regional e global, com posicionamento ético em relação ao cuidado de si mesmo, dos outros e do planeta (BRASIL, 2018, p. 9).

A importância da argumentação é reiterada pela BNCC quando o documento aponta como uma das habilidades dentro das competências a serem desenvolvidas pela área de Ciências Humanas e Sociais Aplicadas:

Elaborar hipóteses, selecionar evidências e compor argumentos relativos a processos políticos, econômicos, sociais, ambientais, culturais e epistemológicos, com base na sistematização de dados e informações de diversas naturezas (expressões artísticas, textos filosóficos e sociológicos, documentos históricos e geográficos, gráficos, mapas, tabelas, tradições orais, entre outros) (BRASIL, 2018, p. 571).

Além de ser apontada pela BNCC como essencial aos alunos da Educação Básica como um todo, vale salientar que a argumentação é imprescindível à atividade filosófica uma vez que sem a utilização dessa prática restaria ao ensino de Filosofia apenas a reprodução de conteúdos de sua história, eliminando o filosofar. Por meio da prática da argumentação filosófica, os alunos poderão se debruçar sobre os conceitos estudados indo à raiz das questões filosóficas e formulando afirmações fundamentadas, sem a utilização de crenças e achismos.

O desenvolvimento da argumentação requer da disciplina Filosofia uma determinada organização que permita ao professor não apenas transmitir conteúdos, mas auxiliar os alunos

\begin{tabular}{|l|l|l|l|l|}
\hline Gonista 2 Dialectus & Ano 9 & n. 20 & Outubro - Novembro 2020 & p. 56-70 \\
\hline
\end{tabular}


no manuseio dos mesmos, de modo a expressar o que aprenderam por meio de textos e na prática discursiva.

Não existe uma receita ou fórmula para que isso aconteça. O professor de Filosofia deve pensar a sua prática constantemente e analisar as ações exitosas e aquelas que não funcionaram com a sua turma. Algumas experiências de ensino chegam até nós e podem nos auxiliar nessa reflexão. Um estudo envolvendo o ensino de Filosofia e, mais especificamente, a prática argumentativa foi desenvolvido pela autora deste $\operatorname{artigo~}^{3}$, durante o Mestrado Profissional em Filosofia - PROF-FILO ${ }^{4}$ entre os anos de 2017 e 2019 (COSTA, 2019).

O estudo de Costa (2019) partiu do pressuposto de que o ensino de Filosofia não consiste apenas na compreensão de teorias filosóficas, mas em uma atividade de reflexão sobre conceitos por meio da qual os alunos possam desenvolver as suas potencialidades no âmbito da argumentação crítica, desenvolvendo seu próprio pensamento, analisando, refletindo e criticando o mundo a sua volta. Neste sentido, o referido estudo está em consonância com a competência argumentativa que, segundo a BNCC (BRASIL, 2018) deverá ser desenvolvida pelos alunos da Educação Básica.

O trabalho de Costa (2019) teve como embasamento teórico o conceito de elenchos presente no corpus platônico e seu método, a metodologia elêntica (SANTOS, 2008) $)^{5}$. A prática dessa metodologia é desenvolvida por Platão e pode ser observada nos diálogos socráticos Laques (ou Da Coragem) (2016), Mênon (2001), O Sofista (1979), Teeteto-Crátilo (1988), Apologia de Sócrates (2002) e Górgias (1980).

O elenchos, retratado nos textos platônicos, é um método baseado no diálogo, onde Sócrates submete as afirmações de seus adversários à prova no intuito de analisar a coerência das mesmas (SANTOS, 2008). Segundo Platão, em Mênon (81c-e), cada pessoa, ao nascer, já traz o conhecimento em si. Porém, esse conhecimento pode estar adormecido. Para relembrar aquilo que já existe em suas mentes, é necessário proceder por meio de um método dialético ascendente, que tem um formato comum. Esse método socrático parte do princípio de que a rememoração consiste em que as pessoas admitam as suas ignorâncias e se abram ao saber.

De acordo com Santos (2008), a prática da metodologia elêntica inicia quando o interlocutor de Sócrates concorda com uma de suas afirmações. A partir desse consenso inicial,

A pesquisa foi realizada na Escola Estadual Amaro Cavalcanti, município de Jardim de Piranhas (RN), e envolveu 5 alunas do Ensino Médio.

4 Núcleo da Universidade do Estado do Rio Grande do Norte (UERN), campus de Caicó (RN).

5 Santos não é o único autor a utilizar a terminologia "metodologia elêntica". No entanto, naquele trabalho, as principais conclusões metodológicas sobre o elenchos foram fundamentadas nesse especialista em Platão.

\begin{tabular}{|l|l|l|l|l|} 
Govista Dialectus & Ano 9 & n. 20 & Outubro - Novembro 2020 & p. $56-70$
\end{tabular}


Sócrates elabora uma série de perguntas que deverão ser respondidas pelo interlocutor até que ele defina corretamente o conceito que está sendo debatido. Quando, mediante o diálogo, o adversário do filósofo cai em contradição, Sócrates o ajuda para que ele refine as suas respostas. Aqueles que admitem o erro continuam no exercício do elenchos e são orientados para que suas respostas sejam mais coerentes. Quando o interlocutor não admite o erro não é possível dar continuidade ao método e o diálogo precisa ser encerrado.

\section{O elenchos como modo de argumentação socrático}

No estudo desenvolvido por Costa (2019), a base para as intervenções pedagógicas nas aulas de Filosofia, foi o diálogo socrático Laques, o qual discute o tema da coragem. Dentro do corpus platônico, é um dos textos onde é desenvolvida a metodologia elêntica. O diálogo inicia com as personagens Lisímaco e Melésias pedindo a opinião de outros dois participantes, Laquete e Nícias, sobre a educação de seus filhos, Tucídides e Aristides. Lisímaco e Melésias tinham dúvidas sobre o que os seus filhos devem saber e em quê deveriam se exercitar para tornarem-se homens honrados. As personagens afirmaram terem recebido a recomendação da prática e disciplina da hoplomaquia ${ }^{6}$, para que seus filhos obtivessem uma boa educação. Laques, no entanto, sugere que Lisímaco e Melésias pedissem conselhos a Sócrates, que estava presente no momento, por julgá-lo mais apto a tratar da questão (LAQUES, 180c).

Sócrates aceita aconselhá-los. Entretanto, usando da ironia, recusa-se a ser o primeiro a falar, afirmando ser o menos experiente entre os participantes do diálogo (LAQUES, 182d). O objetivo de Sócrates era pressionar seus interlocutores a expor as suas opiniões contraditórias sobre o assunto debatido, como a seguir:

\footnotetext{
Sendo eu, porém, o mais moço e o menos experiente, parece-me mais acertado ouvir primeiro o que os outros têm que dizer, para aproveitar-me dos seus ensinamentos. No caso de poder acrescentar algo ao que disserem, exporei francamente minha opinião, esforçando-me por convencê-los e a ti da minha maneira de pensar (LAQUES, 182d).
}

6 A hoplomaquia consistia em combates terrestres realizados "entre homens, relembrando batalhas do passado ou fazendo parelhas de combatentes de acordo com seus armamentos” (GONÇALVES, 2008, p. 51). Esses combates estavam inseridos no contexto das festividades da Antiguidade. As festas eram ocasiões nas quais os governantes reafirmavam o seu poder e os aristocratas tentavam mostrar o seu valor. Apesar da autora citada apresentar a noção de hoplomaquia no contexto das lutas romanas na Antiguidade, esse conceito pode ser associado aos embates realizados na Grécia, os quais, segundo Luiz (2014) ocupavam um relevante papel.

\begin{tabular}{|c|c|c|c|c|}
\hline Rovita Dialeatus & Ano 9 & n. 20 & Outubro - Novembro 2020 & p. $56-70$ \\
\hline
\end{tabular}


Após Laquete e Nícias exporem suas opiniões sobre a prática da hoplomaquia na educação, Sócrates conduziu o diálogo de modo que seus interlocutores percebessem que a discussão sobre a educação se tratava na verdade de uma discussão sobre a virtude e sobre a melhor maneira de comunicá-la à alma dos jovens, de modo a torná-las melhor. Após obter a concordância dos envolvidos no diálogo, Sócrates propõe investigar, inicialmente, apenas uma parte da virtude, "[...] evidentemente, aquela a que tende à disciplina da hoplomaquia, e que todo o mundo pensa ser a coragem, não é assim?" (LAQUES, 190d), obtendo a concordância de Laquete. A passagem a seguir, mostra o início da aplicação do elenchos e o pedido de Sócrates para que Laquete defina a coragem:

Sócrates - Comecemos, portanto, Laquete, por determinar e o que é coragem: de seguida, passaremos a considerar de que maneira ela pode ser comunicada aos moços e até onde estes conseguirão adquiri-la por meio do estudo e do exercício. Começa, portanto, como disse, por explicar-nos o que seja a coragem.

Laquete - Isso, Sócrates, por Zeus, não é difícil de explicar. Como sabes, homem de coragem é o que se decide a não abandonar seu posto no campo de batalha, a fazer face ao inimigo e a não fugir (LAQUES, 190d-e).

A definição de Laquete ainda é incompleta, uma vez que não define o que é a coragem, mas apenas oferece exemplos de atitudes consideradas corajosas. Sócrates prossegue com a inquirição, no intuito de ajudá-lo na formulação de suas conjecturas, pois o diálogo só será bem sucedido se Laquete apresentar uma definição para o conceito discutido, conforme a seguir:

Sócrates - Muito bem, Laquete; mas talvez eu não me tenha exprimido com muita clareza, pois não respondeste ao que eu tinha intenção de perguntar, porém outra coisa. Laquete - Como assim, Sócrates? [...]

Sócrates - Foi por isso que eu disse há pouco que era minha a culpa de não me haveres respondido certo, por eu não ter sabido formular a pergunta. Porque não queria que me dissesses apenas quem é corajoso na infantaria, mas também na cavalaria e em tudo o que for pertinente à guerra, e não apenas na guerra, como também nos perigos do mar, quem revela coragem nas doenças, na pobreza, nos negócios públicos; mais, ainda: quem é corajoso não somente com relação à dor e ao medo, mas também forte contra os apetites e os prazeres, assim quando os enfrenta como quando foge deles. Há também, Laquete, quem revela coragem nessas situações.

Laquete - Muita coragem, até, Sócrates.

Sócrates - Todas essas pessoas são corajosas; umas, porém, revelam coragem nos prazeres; outras, nas tristezas; outras, ainda, nos apetites, e alguns mais nas situações de incutir medo. Mas há, também, quero crer, quem se mostra cobarde em condições idênticas.

Laquete - Perfeitamente.

Sócrates - Que é, portanto, coragem, e que é covardia? Foi isso o que perguntei. Experimenta explicar primeiro o que seja coragem, a qualidade que é sempre a mesma em todas essas situações. [...]

\begin{tabular}{|c|c|c|c|c|}
\hline Qenista Dialectus & Ano 9 & n. 20 & Outubro - Novembro 2020 & p. $56-70$ \\
\hline
\end{tabular}


Laquete - Se tivesse de referir-me à coragem presente a todas essas situações, diria que é uma espécie de perseverança da alma (LAQUES, 190e-192b).

$\mathrm{Na}$ citação anterior, Sócrates utilizou novamente a ironia quando afirmou que Laquete não respondeu corretamente à pergunta feita porque ele não a formulou corretamente. O filósofo instrui Laquete para que este possa responder ao que lhe for indagado. Desse modo, Laquete formula sua primeira definição ao afirmar que coragem é a perseverança da alma. Após isso, Sócrates iniciou o processo de refutação da definição proferida por Laquete.

Laquete concordou com a afirmação de Sócrates de que a coragem é perseverança e excelência moral ao mesmo tempo. Na tentativa de refutar Laquete, Sócrates tentou demonstrar que nem sempre a perseverança é coragem. Pois, em alguns casos a perseverança não é excelente, mas está unida à irreflexão. Nesses casos a perseverança é prejudicial. Ao concordar com Sócrates, afirmando que em alguns casos a perseverança não é coragem, podemos observar a argumentação contraditória de Laquete e a primeira refutação. Laquete admitiu que a coragem não é a perseverança da alma e aceitou a afirmação de Sócrates segundo a qual a coragem é a perseverança unida à razão. Essa é a segunda definição de coragem dada por Laquete. A partir daí, Sócrates conduz o diálogo por meio de sucessivas refutações: inicialmente, cita casos de perseverança aliada à razão onde não há coragem e um exemplo onde a perseverança está aliada à imprudência e há coragem. Nos exemplos de quem gasta seu dinheiro com sobriedade e do guerreiro perseverante e prudente, que luta porque sabe que tem vantagens contra seus inimigos, há perseverança e reflexão, mas não há coragem. No caso do guerreiro que é persistente e imprudente porque luta com inimigos mais poderosos e sabe que provavelmente irá perder, há perseverança e não há racionalidade, mas há coragem. Assim, Sócrates refuta a segunda definição de Laquete de que a coragem é a perseverança unida à razão. Sócrates conseguiu demonstrar que a coragem também pode ser a perseverança ligada à não-razão, ou seja, à imprudência e à insensatez. Todavia, Laquete não aceitou a refutação, não admitiu a conclusão a que chegou o diálogo. Para ele a coragem não pode ser associada à imprudência (LAQUES, 192c-193b).

Outro personagem, Nicias, participa do diálogo e tenta definir o que é a coragem.

Nicias - Logo, se o indivíduo corajoso é bom, será também sábio.

Sócrates - Ouviste, Laquete?

Laquete - Ouvi; porém não compreendo muito bem o que ele quer dizer com isso.

Sócrates - Pois eu penso que compreendo; o que o homem quer dizer é que a coragem é uma espécie de sabedoria. [...]

\begin{tabular}{|l|l|l|l|l|}
\hline Revista Dialectus & Ano 9 & n. 20 & Outubro - Novembro 2020 & p. $56-70$ \\
\hline
\end{tabular}


Nicias - Digo, Laquete, que é o conhecimento do que inspira medo ou confiança, tanto na guerra como em tudo o mais (LAQUES, 194d-195a).

Nícias define a coragem com sendo uma espécie de sabedoria, mais precisamente a sabedoria sobre o que é de temer e o que não é. Mais uma vez, a definição se caracteriza por enumerar qualidades ou características da coragem, as quais não são comuns a todos os casos, e dessa forma, a definição de Nícias é refutada por Laquete, que inicia o processo de refutação da nova definição apresentando um exemplo onde existe o tipo de sabedoria a que Nicias se refere, mas não há coragem. Mesmo assim, Nicias não concorda com a afirmação de Laquete, oferecendo contra argumentos que fazem Laquete negar o que havia dito anteriormente (LAQUES, 195b-d).

Como Laquete não consegue refutar Nicias, Sócrates volta ao diálogo, inserindo outros argumentos na tentativa de refutar o argumento inicial de Nícias. Nessa parte do texto platônico, citada anteriormente, Nicias concorda com Sócrates quanto às coisas que são ou não de temer. Para Nicias, essas coisas podem estar no passado, no presente ou no futuro. Desse modo, Nicias aceita a afirmação de que a coragem é o conhecimento das coisas más e boas do presente, do passado e do futuro. Com base nessa afirmação, Sócrates dá continuidade ao procedimento de refutação e consegue, finalmente, a aceitação de Nícias de que não é possível definir a coragem (LAQUES, 199c-e).

O processo de análise do elenchos presente no diálogo platônico Laques, conforme exposto, foi realizado durante a pesquisa da autora em uma turma do Ensino Médio, no qual foi possível perceber que essa metodologia socrática é permeada, em todas as suas etapas, pela argumentação filosófica. No estudo da metodologia elêntica realizado, o objetivo principal foi o de melhorar a prática argumentativa das alunas. O resultado do trabalho demonstrou uma evolução no desempenho geral das pesquisadas. Elas avançaram no que se refere à escrita de textos autênticos, não se prendendo à mera reprodução de ideias de outros autores. Passaram a desenvolver argumentos válidos, sólidos e coerentes e a definir melhor os conceitos utilizados nos textos. Na investigação citada, foram dadas algumas sugestões de estudos que poderão ser realizados futuramente. A primeira sugestão diz respeito aos impactos da BNCC no Ensino de Filosofia.

\section{O Ensino de Filosofia e a BNCC}

\begin{tabular}{|c|c|c|c|c|}
\hline Ronista Qialectus & Ano 9 & n. 20 & Outubro - Novembro 2020 & p. $56-70$ \\
\hline
\end{tabular}


Ainda não se sabe como a reforma do Ensino Médio amparada pela BNCC impactará tal ensino. Todavia, é possível vislumbrar que, uma vez tendo perdido o caráter de disciplina, os conteúdos de Filosofia ficarão diluídos na grade curricular, tornando-se ainda mais limitados.

Os conhecimentos de Filosofia estão inseridos nas competências e habilidades apontadas para a área de Ciências Humanas e suas Tecnologias. De acordo com Conceição (2020, p. 1), embora a BNCC trabalhe a partir de áreas de conhecimento, as disciplinas tradicionais estão presentes nas competências e habilidades. Além disso, ainda segundo o autor (2020, p. 1), "é possível encontrar cruzamentos entre as habilidades dessas disciplinas [...], levando em conta seus objetos de conhecimento ou seus processos cognitivos". O estudo de Conceição (2020) aponta possibilidades, a partir da BNCC, de ações interdisciplinares envolvendo conhecimentos de Língua Portuguesa e Filosofia. As ações propostas, segundo Conceição (2020, p. 1) passam "por temas como ética e epistemologia, instrumentos como análise e composição de argumentos, até alguns aspectos socioafetivos”.

Concordamos com Conceição (2020) quando o mesmo afirma que as disciplinas tradicionais estão presentes nas competências e habilidades da BNCC e quanto às possibilidades de se trabalhar os conteúdos das diferentes áreas do saber de forma interdisciplinar. É necessário romper as barreiras das disciplinas e superar o isolamento existente entre as mesmas. Os saberes das diferentes disciplinas que compõem a atual grade curricular das escolas brasileiras precisam dialogar. Porém, não se deve fazer isso retirando das mesmas o tempo destinado a abordar os seus conteúdos conceituais. Para que a interdisciplinaridade aconteça é necessário partir do conjunto estrutural de saberes que compõem cada disciplina. Como os alunos desenvolverão as habilidades de argumentar e debater conceitos filosóficos sem antes terem dedicado tempo ao estudo desses conceitos?

De acordo com Fávero, Centenaro e Santos (2020), a flexibilização proposta pela BNCC pode levar a exclusão da Filosofia e de outros componentes curriculares do Ensino Médio. Segundo os autores (FÁVERO; CENTENARO; SANTOS, 2020. p. 4-5),

A não obrigatoriedade da filosofia permite aos sistemas de ensino - públicos e privados - organizar a oferta da disciplina conforme considerarem necessário, havendo aí precedente para oferta mínima ou não oferta, já que a lei obriga apenas o ensino de práticas e estudos. Além disso, os sistemas de ensino podem estruturar itinerários formativos de ciências humanas e sociais aplicadas, entretanto, eles são optativos, ou seja, o aluno pode escolher não cursar um itinerário de humanas, por exemplo. Se confirmadas e implementadas as reformas, uma diversificada gama de conteúdos, práticas e abordagens ligadas à filosofia deixarão de compor a formação

\begin{tabular}{|c|c|c|c|c|}
\hline Q Rovita Oilatectus & Ano 9 & n. 20 & Outubro - Novembro 2020 & p. $56-70$ \\
\hline
\end{tabular}


básica dos estudantes brasileiros, o que representa um profundo retrocesso diante dos próprios parâmetros constitucionais do Art. 205, os quais estabelecem que a educação visa ao "pleno desenvolvimento da pessoa, seu preparo para o exercício da cidadania e sua qualificação para o trabalho" (BRASIL, 1988), bem como para o desenvolvimento do pensamento reflexivo.

Apesar de estarem presentes nas competências e habilidades preconizadas pela BNCC, os conhecimentos conceituais de Filosofia, bem como a prática do filosofar, podem ser reduzidos nos currículos escolares.

Outra questão que pode ser levantada com relação à BNCC é quanto à formação específica para se atuar em cada área de conhecimento da Base comum e dos Itinerários formativos. Uma vez que se trabalha por competências e habilidades e não por disciplinas, entendemos que um professor formado em uma determinada área do saber poderá ministrar conteúdos comuns a várias disciplinas tradicionais. Fica a seguinte questão: A formação acadêmica dos professores do sistema de ensino brasileiro fornece subsídios suficientes para que os mesmos trabalhem os conteúdos conceituais presentes nas diferentes disciplinas e contribua para o desenvolvimento das competências e habilidades presentes na BNCC?

Cada disciplina escolar tem suas especificidades e requerem dos professores, além do domínio dos conteúdos conceituais, um "saber fazer" e uma postura específica diante da turma. A formação dos professores que irão atuar em cada uma das disciplinas escolares deverá atender a essas particularidades. Um professor que não possui formação específica para ministrar uma determinada disciplina terá maior propensão a não atender ao esperado.

No que se refere ao ensino de Filosofia, a formação de professores deverá contemplar além dos conteúdos conceituais, que se referem à história da filosofia, uma atitude que é própria do filosofar. De acordo com Rodrigo (1987, p. 23),

Talvez, mais importante do que o conteúdo em si seja a postura que orientará a prática pedagógica do professor de Filosofia no dia-a-dia da sala de aula [...] trata-se de uma ruptura com as concepções cristalizadas do senso comum, mostrando que a Filosofia começa com a problematização daquilo que parece óbvio no mundo cotidiano. Mais do que ensinar um conteúdo, é preciso instaurar uma postura filosófica que comece por duvidar que a realidade seja um dado. Em suma, o que se propõe é um trabalho docente calcado numa concepção que enfatiza a Filosofia como reflexão, descartandose a erudição filosófica como um fim em si mesmo.

A postura da qual fala Rodrigo (1987) deve começar a ser construída nos cursos de Ensino Superior para formação de professores de Filosofia e se estender ao longo de sua carreira. Um professor que não tenha essa formação em Filosofia dificilmente terá uma postura filosófica. Professores com outra formação, mesmo fazendo parte da área de Ciências Humanas

\begin{tabular}{|l|l|l|l|l|}
\hline Govista Dialectus & Ano 9 & n. 20 & Outubro - Novembro 2020 & p. 56-70 \\
\hline
\end{tabular}


e suas tecnologias não estão aptos a ensinar Filosofia, pois “ [...] o ensino de filosofia distinguese de qualquer outro tipo de ensino, pois é um ensino filosófico. Exige da parte do professor a consciência da atitude filosófica." (ZUBEN, 1992, p. 8).

Essa afirmação é reiterada por Sousa (2017, p. 80) quando afirma o seguinte:

\begin{abstract}
Entendemos que a filosofia no ensino médio deve ser praticada por educadores com formação acadêmica na disciplina, porque, somente estes têm condições de manejar adequadamente os conteúdos e abordá-los com mais precisão com educandos do ensino médio, fomentando a criticidade, debates e o pensamento autônomo do alunado. Ademais, o professor graduado em filosofia, tem mais condições de conduzir o estudante à busca da maioridade intelectual, auxiliando-o a problematizar a realidade com mais criticidade, e a superar as superficialidades presentes no contexto social (ideologias, etc.).
\end{abstract}

Conforme apontado por Sousa (2017), é importante que a Filosofia seja ensinada por alguém com graduação na área, pois a ausência de tal profissional poderá comprometer os resultados do ensino. O professor com formação em outra área poderá seguir a crença do senso comum segundo a qual para que a aula seja de Filosofia basta refletir ou debater sobre algo (DUTRA, 2014) ou dar apenas um tratamento histórico à disciplina, eliminando a reflexão. As dificuldades enfrentadas por professores de Filosofia sem formação na área são apontadas por um estudo desenvolvido por Lima (2012), entre os anos de 2008 e 2010, com professores da cidade de Miracema do Tocantins, localizada no estado de Tocantins. O estudo demonstrou que os professores pesquisados atuavam no ensino de Filosofia sem terem formação na área. Os mesmos apresentavam dificuldades tanto para entender os conteúdos da referida disciplina como para utilizar metodologias que facilitassem a aprendizagem (LIMA, 2012, p. 257). De acordo com Lima (2012, p. 260), no início da pesquisa, os professores não demonstraram interesse em tentar entender os textos de natureza filosófica. Quanto aos procedimentos metodológicos adotados em sala de aula, um dos professores afirmou que nas aulas de Filosofia limitava-se a escrever sobre a biografia de alguns filósofos.

Desse modo, entendemos que os conhecimentos de Filosofia deverão ser ministrados por um licenciado em Filosofia. A menos que haja uma reestruturação do Ensino Superior para formar professores aptos a atuarem em diferentes campos do saber, a BNCC contribui para a deterioração da Filosofia no Ensino Médio.

\title{
Referências
}

\begin{tabular}{|c|c|c|c|c|}
\hline Rovista Dialectus & Ano 9 & n. 20 & Outubro - Novembro 2020 & p. $56-70$ \\
\hline
\end{tabular}


BRASIL. Medida Provisória ${ }^{\circ}$ 746, de 22 de setembro de 2016. Institui a Política de Fomento à Implementação de Escolas de Ensino Médio em Tempo Integral, altera a Lei n 9.394, de 20 de dezembro de 1996, que estabelece as diretrizes e bases da educação nacional, e a Lei n $^{\circ}$ 11.494 de 20 de junho 2007, que regulamenta o Fundo de Manutenção e Desenvolvimento da Educação Básica e de Valorização dos Profissionais da Educação, e dá outras providências. Disponível em: https://www.congressonacional.leg.br/materias/medidas-provisorias//mpv/126992. Acesso em: 07 fev. 2019.

BRASIL. Lei no 13.415, de 16 de fevereiro de 2017. Altera as Leis nos 9.394, de 20 de dezembro de 1996, que estabelece as diretrizes e bases da educação nacional, e 11.494, de 20 de junho 2007, que regulamenta o Fundo de Manutenção e Desenvolvimento da Educação Básica e de Valorização dos Profissionais da Educação, a Consolidação das Leis do Trabalho - CLT, aprovada pelo Decreto-Lei no 5.452, de 1 o de maio de 1943, e o Decreto-Lei no 236, de 28 de fevereiro de 1967; revoga a Lei no11.161, de 5 de agosto de 2005; e institui a Política de Fomento à Implementação de Escolas de Ensino Médio em Tempo Integral. Brasília, 2017a. Disponível em: http://www.planalto.gov.br/ccivil_03/_Ato2015-2018/2017/Lei/L13415.htm. Acesso em: 02 jan. 2018.

BASIL. Resolução CNE/CP n ${ }^{\circ}$ 2, de 22 de dezembro de 2017. Institui e orienta a implantação da Base Nacional Comum Curricular, a ser respeitada obrigatoriamente ao longo das etapas e respectivas modalidades no âmbito da Educação Básica. Brasília, 2017b. Disponível em: http://portal.mec.gov.br/observatorio-da-educacao/323-secretarias-112877938/orgaosvinculados-82187207/53031-resolucoes-cp-2017. Acesso em: 07 fev. 2019.

BRASIL. Ministério da Educação. Secretaria da Educação Básica. Base Nacional Comum Curricular: educação é a base: Ensino Médio. Brasília: Secretaria de Educação Básica, 2018. Disponível em: http://basenacionalcomum.mec.gov.br/wpcontent/uploads/2018/12/BNCC_19dez2018_site.pdf. Acesso em: 07 fev. 2019.

CONCEIÇÃO, Thiago Gruner. Que interdisciplinaridade a BNCC oferece à Filosofia? Aproximações à língua portuguesa. REFilo - Revista Digital de Ensino de Filosofia, v. 6, p. 1 - 10, 2020. Disponível em: https://core.ac.uk/download/pdf/287358353.pdf. Acesso em 22 ago. 2020.

COSTA, Izanete de Medeiros. O estudo da metodologia elêntica dos diálogos platônicos e a argumentação crítica no Ensino Médio. 2019. 125 f. Dissertação (Mestrado Profissional em Filosofia) - Universidade do Estado do Rio Grande do Norte. Natal. Disponível em: http://www.uern.br/controledepaginas/proffilo-dissertacoes-

defesa2019/arquivos/5400o_estudo_da_metodologia_elentica_dos_dielogos_platonicos_e_a_ argumentacao_critica_no_ensino_medio.pdf. Acesso em 22 ago. 2020.

DUTRA, Jorge da Cunha. A relevância da filosofia como disciplina escolar no currículo do Ensino Médio. 2014. 330 f. Tese (Doutorado em Educação) - Faculdade de Educação, Universidade Federal de Pelotas. Pelotas. Disponível em: http://repositorio.ufpel.edu.br:8080/bitstream/prefix/3191/1/DUTRA\%2c\%20Jorge\%20da\%2 0Cunha.pdf. Acesso em: 20 mai. 2017.

\begin{tabular}{|c|c|c|c|c|}
\hline Revista Dialeatus & Ano 9 & n. 20 & Outubro - Novembro 2020 & p. $56-70$ \\
\hline
\end{tabular}


FÁVERO, Altair Alberto; CENTENARO, Junior Bufon; SANTOS, Antonio Pereira dos. Reformas curriculares e o ataque ao pensamento reflexivo: o sutil desaparecimento da filosofia no currículo da Educação Básica no Brasil. REFilo - Revista Digital de Ensino de Filosofia,

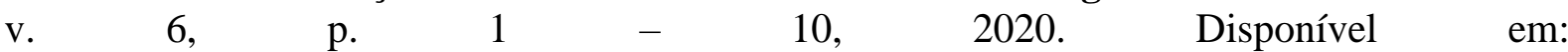
https://www.researchgate.net/profile/Junior_Centenaro/publication/343448032_Reformas_cur riculares_e_o_ataque_ao_pensamento_reflexivo_o_sutil_desaparecimento_da_filosofia_no_c urriculo_da_Educacao_Basica_no_Brasil_Curricular_reforms_and_attack_on_reflective_thin king_the_subtle_/links/5f2aa98e299bf13404a2c3d4/Reformas-curriculares-e-o-ataque-aopensamento-reflexivo-o-sutil-desaparecimento-da-filosofia-no-curriculo-da-Educacao-Basicano-Brasil-Curricular-reforms-and-attack-on-reflective-thinking-the-subtle.pdf. Acesso em 22 ago. 2020.

GONÇALVES, Ana Teresa M.. As festas romanas. Revista de Estudos do Norte Goiano, v. 1 n. $\quad 1, \quad 2008, \quad$ p. $26 \quad-\quad 68 . \quad$ Disponível em: https://historia.ufg.br/up/108/o/as_festas_romanas_ana_teresa.pdf. Acesso em: 03 mar. 2019

LIMA, Márcio Antônio Cardoso. Experiência com o ensino de Filosofia, por meio da pesquisaação, com professores da diretoria regional de ensino da cidade de Miracema do Tocantins TO. Revista Diálogos educacionais, Curitiba, v. 12, n. 35, p. 253-275, 2012. Disponível em: https://periodicos.pucpr.br/index.php/dialogoeducacional/article/view/5074. Acesso em: 02 fev. 2019.

LUIZ, Felipe. Precisões sobre o conceito de filosofia da guerra. Filogênese, v. 7, n. 2, 2014, p. 01-14. Disponível em: https://www.marilia.unesp.br/Home/RevistasEletronicas/FILOGENESE/2_felipeluiz.pdf. Acesso em: 04 mar. 2019.

PLATÃO. O Sofista. In: Diálogos: O Banquete, Fédon, Sofista, Político. Tradução e notas de José Cavalcante de Souza. 2. ed. São Paulo: Abril Cultural, 1979. p. 129 - 195.

PLATÃO. Górgias. Tradução de Carlos Alberto Nunes. Belém: Universidade Federal do Pará, 1980. Disponível em: http://bocc.ubi.pt/ fidalgo/retorica/platao-gorgias.pdf. Acesso em: Acesso em: 07 jun. 2017.

PLATÃO. Teeteto-Crátilo. Tradução de Carlos Alberto Nunes. Belém: Gráfica e Editora Universitária UFPA, 1988.

PLATÃO. Mênon. Edição bilíngüe grego-português. Tradução de Maura Iglésias. São Paulo: Loyola; Rio de Janeiro: PUC-Rio, 2001.

PLATÃO. Apologia de Sócrates. Tradução de Maria Lacerda de Moura. 19. ed. São Paulo: Ediouro, 2002.

\begin{tabular}{|c|c|c|c|c|}
\hline Q Rovita Dialectus & Ano 9 & n. 20 & Outubro - Novembro 2020 & p. $56-70$ \\
\hline
\end{tabular}


PLATÃO. Laques (ou Da Coragem). In.: Diálogos VI: Crátilo (ou Da Correção dos Nomes), Cármides (ou Da Moderação), Laques (ou Da Coragem), Ion (ou Da Ilíada) e Menexeno (ou Oração Fúnebre). 2. ed. Tradução de Carlos Alberto Nunes. São Paulo: Edipro, 2016.

RODRIGO, Lidia Maria. Da ausência à presença da Filosofia: o desafio da iniciação à reflexão filosófica. Educação e Filosofia, Uberlândia, v. 1, n. 2, p. 19-23, 1987. Disponível em: http://www.seer.ufu.br/index.php/EducacaoFilosofia/article/view/1986/1655. Acesso em 22 ago. 2020.

SANTOS, José Trindade. Para ler Platão. Tomo I. A ontoepistemologia dos diálogos socráticos. São Paulo: Loyola, 2008.

SOUSA, Kairon Pereira de Araújo. A Filosofia no Ensino Médio: alguns desafios. Revista Espaço Acadêmico, v. 17, n. 195, p. 70-81, 2017. Disponível em: http://www.periodicos.uem.br/ojs/index.php/EspacoAcademico/article/view/34211/20480.

Acesso em: 08 nov. 2018.

ZUBEN, Newton Von A. Filosofia e Educação: atitude filosófica e a questão da apropriação do filosofar. Pro-posições, Campinas, v. 3, n. 2, p. 7-27. 1992. Disponível em: https://periodicos.sbu.unicamp.br/ojs/index.php/proposic/article/view/8644401/14986. Acesso em 22 ago. 2020.

\begin{tabular}{|l|l|l|l|l|}
\hline Q & Ano 9 & n. 20 & Outubro - Novembro 2020 & p. $56-70$ \\
\hline
\end{tabular}

